\title{
Meio Ambiente, Desenvolvimento e Turismo: uma proposta de conciliação - o caso do município de Guaraqueçaba - PR, Brasil
}

\author{
Environment, Development and Tourism: a conciliation proposal \\ - the case study of Guaraqueçaba County - PR, Brazil
}

\author{
Jefferson Marçal da Rocha ${ }^{1}$
}

\begin{abstract}
RESUMO: Este texto analisa a controversa relação entre sociedade e meio ambiente, na perspectiva de entender como se constituem na práxis as propostas que visam alcançar o normativo objetivo: desenvolvimento sustentável. Para isso, analisa-se o caso do município de Guaraqueçaba que, nas últimas décadas, tem sofrido conseqüências diretas do embate entre sociedade e meio ambiente. Assim, o turismo tornou-se uma alternativa para a comunidade local, porém o desconhecimento dos mecanismos de funcionamento desse mercado, aliado à trajetória histórica da localidade não possibilitaram que essa potencialidade se tornasse efetivamente conciliadora das demandas de preservação e desenvolvimento socioeconômico.
\end{abstract}

PALAVRAS-CHAVE: meio ambiente; agricultura; turismo.

ABSTRACT: This article makes a particular link between the concepts of society and environment, in a perspective that it seeks to reach a normative objective: sustainable development. In this perspective, the case of the municipality of Guaraqueçaba is studied, within a period of ten years. The results show that this area has been suffering direct consequences of the confrontation between society and environment. In such situation, tourism has become an alternative for thelocal community. However the ignorance of such mechanisms

1. Economista. Doutor em Meio Ambiente e Desenvolvimento. Professor titular do Departamento de Economia e do Mestrado em Turismo da Universidade de Caxias do Sul - UCS-RS; professor da Universidade da Região da Campanha - URCAMP e do Centro Universitário do Vale do Taquari - UNIVATES. Contato: UCS - Rua Francisco Getúlio Vargas, 1130 bloco 46 sala/312 - 95070-560 - Caxias do Sul-RS; e-mail: jmrocha@ucs.br. 
to operate in the tourism market, merged with the historical path of the region made it impossible to enhance the convergence of preservation and tourism in a socio-economic matter.

KEYWORDS: environment; agriculture; tourism.

\section{Introdução}

Este texto trata de dois importantes e complexos aspectos contemporâneos que estão presentes de forma concreta na área geográfica estudada - o município de Guaraqueçaba, correlacionados e dependentes entre si: (1) o desenvolvimento endógeno sustentável e (2) a preservação dos recursos naturais. Esses dois temas, nos últimos anos, têm perpassado as discussões entre as ciências da natureza e as ciências sociais. Para uma discussão empírica desses dois aspectos, analisa-se o projeto de desenvolvimento sustentável Geração de Renda para a Comunidade do Morato, proposto pela Organização Não-governamental - ONG Fundação O Boticário, que vê no turismo ecológico um potencializador da sustentabilidade, tanto no que se refere à reprodução socioeconômica da comunidade local como dos recursos naturais que as rodeiam.

Neste artigo, a proposta é avaliar como os interesses de preservação ambiental da região estudada, supostamente de interesse da sociedade em geral, conflitam com a necessidade de reprodução socioeconômica da comunidade autóctone.

O município de Guaraqueçaba, onde se encontra a maior parte da Área de Proteção Ambiental - APA homônima, situa-se no litoral norte do estado do Paraná. Por suas características naturais, essa região consta na UNESCO como Reserva da Biosfera Planetária e, desde 1985, passou a ser considerada Unidade de Conservação - UC nacional e estadual - APA de Guaraqueçaba. Sua população gira em torno de oito mil habitantes, constituída em sua maioria de agricultores, coletores e pescadores, os quais, nos últimos anos, por causa da forte aplicação da legislação ambiental imposta à região e também em função de suas práticas produtivas historicamente utilizadas, têm sofrido restrições para manterem seus meios de vida - especialmente agricultura, pesca e coleta.

O texto está divido em cinco partes: a primeira faz uma análise histórica do controverso tema Desenvolvimento Sustentável; a segunda traz uma trajetória de como a nova concepção de turismo potencializou a prática de atividades turísticas em regiões até então pouco consideradas para esse fim; a terceira relata como foram construídas a demanda e as estratégias para o projeto geração de renda para a comunidade local; a quarta relata o projeto desenvolvido pela Fundação O Boticário, especialmente em relação às suas nuances sociais; e, por último, nas considerações finais, analisam-se, à luz do empírico, as conotações teóricas do tema proposto, este ainda longe de ser elucidado, mas nem por isso menos instigante.

\section{Desenvolvimento sustentável: uma construção histórico-social}

A preocupação com a sustentabilidade socioambiental da sociedade moderna, mesmo ainda sem esse rótulo, vem de meados do século XIX. Isso porque a humanidade sempre interagiu com o meio ambiente, provocando efeitos negativos, em maior ou menor grau, conforme a época e/ou forma de utilização dos recursos. McCormick (1989 apud Marzall, 1999) considera que o movimento ambientalista não tem um marco claro de como nem onde iniciou e muito menos se disseminou pelo mundo da mesma forma, porquanto surgiu em lugares diferentes, por motivos diferentes e em épocas diferentes. Contudo, para este pesquisador há uma certeza: a preocupação com a questão ambiental teve seu início em problemas locais.

A problemática ambiental surgiu na era das descobertas científicas, e esse crescente interesse pela história natural permitiu revelar concretamente as conseqüências da relação de exploração que o homem teve com a natureza. A obra de Gilbert White, por exemplo, The Natural History of Selborne, publicada em 1788, teve grande influência em sucessivas gerações de naturalistas, inclusive no mais famoso deles, Charles Darwin.

Nos Estados Unidos, o livro Man and Nature, de George Perkins Marsh, publicado em 1864, é considerado um marco do ambientalismo americano. Nele o autor já chamava a atenção para o fato de a destruição dos recursos naturais estarem tornando a Terra inabitável para todos os seres vivos. Essas duas obras, mesmo que importantes, não levaram a avanços concretos rumo a mecanismos de exploração dos recursos naturais menos impactantes. Além de terem caráter próximo a previsões catastróficas, ficaram quase que restritos às áreas das ciências naturais.

Foi só no princípio do século XX que movimentos mais efetivos para defesa dos recursos naturais começaram a ser percebidos. Contudo, embora mais estruturados, ainda se mostravam esparsos (Acselrad, 2001).

Somente após o fim da Segunda Grande Guerra é que os primeiros sinais do que se pode chamar revolução ambiental internacional foram observados em razão, entre outros motivos, dos testes nucleares, do rápido crescimento da indústria e do consumo, dos problemas causados pelas grandes aglomerações urbanas, da poluição dos recursos hídricos etc.

Em termos de política internacional, a Conferência das Nações Unidas sobre a Conservação e Utilização de Recursos, em 1949, foi o primeiro marco dessa nova trajetória ambientalista (Marzall, 1999). Nessa conferência, reconhece-se que a crescente pressão sobre os recursos naturais (florestas e animais) exercida pela atividade 
antrópica levaria a um mundo insustentável. Nessa perspectiva, são elencadas a importância da educação ambiental e a integração da gestão de bacias hidrográficas, sendo essa segunda proposta motivada pela visível degradação por que passavam os rios europeus. Porém, esses objetivos não chegaram a impor compromissos aos governos. Apenas sugeriam alguns intercâmbios de experiências, mais precisamente entre países limítrofes da Europa. McCormick apud Marzall (1999) afirma que, nesse evento, as idéias sobre os reais problemas planetários do meio ambiente eram precoces, por isso as estratégias para solucioná-los foram consideradas softs.

Mais duas décadas se passaram para que a questão ambiental começasse a tomar forma mais definitiva no âmbito da política internacional. Isso se deu na Conferência Intergovernamental para o Uso Racional e Conservação da Biosfera organizada pela United Nations Educational, Scientific and Cultural Organisation - UNESCO em 1968. Apesar da constatação de que os problemas tinham se agravado, nenhuma proposição mais concreta foi sugerida nessa conferência (Le Preste, 2000).

Em termos científicos, um dos grandes impulsos no movimento ambientalista ocorreu em 1962, quando a bióloga norte-americana Rachel Carson lançou o livro intitulado Silent Spring (Primavera silenciosa). Essa publicação, mesmo não sendo a primeira em seu gênero, é ainda hoje considerada uma referência, para não dizer o marco da revolução ambientalista mundial (McCormick, 1992; IISD, 1997c apud Marzall, 1999). O veredicto de Carson estava claro e comprovadamente assustador: se não parasse a utilização de agroquímicos na produção de grãos, as próximas primaveras seriam silenciosas, e pássaros não mais existiriam. Em palavras mais claras: os precedentes dessa geração conheceriam muitas espécies apenas por catálogos ornitólogos (Leis, 1999).

Apesar das restrições impostas à circulação, pois foi barrado durante alguns anos por editores americanos, além de ter sido escrito em inglês e sem tradução para o português até os dias de hoje (2005), por exemplo, seu livro teve grande repercussão, tanto entre ambientalistas como no meio acadêmico e científico e ainda junto a segmentos da sociedade de modo geral, os quais tomam, pela primeira vez, consciência da gravidade da questão ambiental. O mérito desse livro foi motivar, a partir daí, em muitas regiões e países, uma "cobrança" mais efetiva de governos, por políticas e atitudes mais concretas no que se referia à preservação dos recursos naturais. Não só porque esses recursos eram um importante ativo local, como por fazerem parte de um sistema de interesse global - o ecossistema planetário (Neder, 2001).

Dois importantes desastres no final dos anos 1960 também fomentaram a discussão: um vazamento de petróleo no mar próximo à costa americana e a contaminação por mercúrio na Bacia de Minamata, no Japão. Este último provocou graves disfunções neurológicas, inicialmente em cães e, posteriormente, também em seres humanos (Rocha, 2002b).
Já no campo político internacional, o marco do reconhecimento da problemática ambiental foi o polêmico relatório do Clube de Roma de 1968, conhecido como os Limites do Crescimento. Morin (1997) sugere que as previsões e os prognósticos do Clube de Roma tenham a mesma representatividade, no contexto do movimento ambientalista, que os primeiros mapas dos navegadores árabes tiveram na idade Média. Não configuravam corretamente a geografia do mundo, enganaram-se, em muitos casos, completamente, sobre as posições dos continentes e mares, mas “[...] tinham o grande mérito de esforçar-se em refletir sobre o mundo que conheciam e em representá-lo tão precisamente quanto podiam” (Morin, 1997: 57). Deve-se levar em conta, tanto nos mapas dos árabes quanto no relatório do Clube de Roma, uma característica muito comum entre os economistas, ou seja, a chamada condição coeteris paribus (tudo o mais permanecendo constante) das variáveis disponíveis para a análise. Essa condição limitava a análise a técnicas e teorias presentes. Talvez daí as críticas que esse relatório sofreu em quase todos os países ocidentais.

Contudo, o relatório Limites do Crescimento (Meadows, 1972), do Clube de Roma, foi recebido com enorme preconceito, principalmente entre políticos e cientistas dos países pobres, por preconizar "crescimento zero" para as nações como forma de reduzir impactos do crescimento sobre o meio ambiente, o que limitava, portanto, o processo de crescimento desses países rumo ao "Primeiro Mundo". Vale lembrar que, na década de 1970, a maioria dos países subdesenvolvidos estava engajada em um projeto de desenvolvimento rápido, em especial a América Latina. A reação da maioria dos governos dessa região era contrária a qualquer forma de limitar este crescimento (CMMDA, 1991; Rocha, 2002).

Os limites do crescimento e os desastres ambientais amplificaram os debates internacionalmente, culminando em uma série de encontros internacionais e na criação de diversos programas por organismos internacionais como a United Nations Environmental Program (UNEP), cujo enfoque era a problemática da contaminação dos recursos hídricos por metais pesados e o uso do DDT (diclorodifeniltricloruetano) (Sachs, 1993; Urban, 2001).

Foi em 1971, na Conferência de Founex (Suíça) que se abordou, mais objetivamente, a importância de integrar o meio ambiente às estratégias de desenvolvimento. Discutiam-se, especialmente, os efeitos colaterais sobre o meio ambiente provocados pela atividade agrícola. Logo em seguida, em 1972, aconteceu a famosa Conferência de Estocolmo, que havia sido preparada em Founex. Nesses dois eventos, foram apresentados estudos sobre a constante degradação dos recursos naturais planetários. Entre os princípios redigidos na Carta de Estocolmo, um chamava a atenção: a necessidade de uma nova postura civilizatória, na qual a utilização dos recursos naturais deveria atender às necessidades das gerações presentes, assim como garantir o suprimento das necessidades das gerações futuras. Este, afinal, acabou 
sendo instituído como conceito de desenvolvimento sustentável ${ }^{2}$ mais aceitável (Brundtland,1991; Foladori, 1999).

Outras questões, mais práticas, também constaram nesse relatório: a preocupação com a contaminação ambiental dos recursos hídricos, a importância de instituir programas de conservação mundial para os recursos naturais, os problemas decorrentes do fornecimento de energia, a diminuição da disponibilidade de petróleo etc. (Goulet, 2001).

No início da década de 1980, a UICN publicou um documento intitulado Estratégia de Conservação Mundial (World Conservation Strategy). Nesse estudo consta uma seção intitulada "Em direção ao Desenvolvimento Sustentável", que, para Kirkby et al. (apud Marzall, 1999), é a primeira vez em que o termo sustentabilidade aparece como um objetivo a ser alcançado.

Já em 1983 foi formada na ONU a Comissão Mundial para o Meio Ambiente e Desenvolvimento - CMMDA. Essa comissão, depois de três anos de trabalhos, publicou, em 1987, o Relatório Brundtland, " “Nosso Futuro Comum”. A principal preocupação dessa comissão era com a crescente escassez dos recursos naturais e com o aumento da pobreza e da miséria de grande parte da população mundial. A pobreza passou a ser vista, concomitantemente, tanto como causa quanto como efeito dos problemas ambientais. Esse documento considerava que a crise gerada pelos problemas ambientais não tinha uma única origem, nem especificidade de espaço geográfico ou aspecto social. Porém, para reduzir-se a degradação ambiental, tinha-se que reduzir também a pobreza (Middleton \& O'Keefa, 2001).

No capítulo 14 da Agenda 21 (Documento gerado na Rio-92 - encontro ambientalista realizado na cidade do Rio de Janeiro, em junho de 1992, CNUMAD), dedicado à agricultura sob o enfoque do desenvolvimento sustentável, o turismo é mencionado como atividade viável em regiões onde não é possível intensificar a aplicação dos sistemas de exploração agrícola. Essa é uma perspectiva limitada, pois, na realidade, o desenvolvimento de atividades turísticas tem se dado no meio rural como complemento das atividades agrícolas tradicionais de grande número de pequenos agricultores familiares.

Na prática, o que se observa é que, a partir do Relatório da CMMDA, o termo desenvolvimento sustentável disseminou-se. Em outras palavras, seu uso tornou-se corrente em praticamente todos os setores da vida social. Passou a ser politicamente correto falar em sustentabilidade, mesmo sem ainda definir-se claramente

2. Não cabe aqui uma descrição das controvérsias que esse termo possui, porém cabe salientar que, tanto nas ciências sociais como nas ditas naturais, há ainda pouco consenso do real significado desse termo (Raynaut, 1994).

3. Essa denominação se deve ao fato de ter sido presidida pela primeira ministra da Noruega, Gro Brundtland. o que isso significa. Talvez por isso seja pregado por tantos e esteja presente em diferentes contextos, às vezes pouco ligados à percepção real da problemática ambiental (Rocha, 2004).

\section{Do turismo de massa ao turismo rural-ecológico}

A atividade turística é filha legítima da Revolução Industrial. Na sua fase moderna, teve seu início como fenômeno de massa durante o século XIX na Grã-Bretanha. O primeiro marco dessa fase foi a viagem organizada por Thomas Cook, em 1841, com o objetivo de levar de Londres até Longboroug, na Inglaterra, 570 passageiros para um congresso (Trigo, 1996). Segundo Dias (2003), esse acontecimento marca o início da época "moderna do turismo". Surge, assim, o turismo como atividade de negócio, no qual a função de organizar o transporte de pessoas de seus domicílios para outros lugares torna-se um investimento com possibilidade de lucro (Barretto, 2004).

Assim, sua característica socioeconômica não foge muito à regra do processo de desenvolvimento dos demais setores produtivos, como a exploração dos recursos naturais e a utilização de trabalhadores e capital em vista da maximização de suas utilidades, ou, de outro modo, a busca de lucros diante dos capitais investidos. Isso porque o modelo capitalista de livre mercado submeteu a uma "única" racionalidade econômica todas as atividades produtivas.

Barretto (2004: 134), em seu trabalho sobre as relações entre visitantes e visitados, também vê "[...] no turismo, velhos problemas que acompanham a história social da humanidade, como o colonialismo cultural e a xenofobia, e que as relações interpessoais acabam seguindo a lógica mercantil, ou seja, são comercializadas como bem de consumo".

Assim, o turismo tido convencional, enquanto um de seus segmentos econômicos, é por definição altamente consumidor de recursos naturais. Durante boa parte do século XX, houve uma profunda interdependência entre a atividade turística e os recursos naturais (Faria \& Carneiro, 2001). Somente entre as décadas de 1970 e 1980 do século XX, quando o modelo de desenvolvimento imposto à sociedade ocidental começa a ser questionado, não só por causar desajustes sociais - dividindo cada vez com mais profundidade as classes sociais, como os diagnosticados por Marx ainda na metade do século XIX - mas também por causar males irreversíveis aos recursos naturais do planeta, é que cientistas intelectuais, políticos, pesquisadores, governantes, membros de organizações internacionais, etc., concluem que será impossível à grande maioria do planeta chegar a níveis próximos do desenvolvimento dos países ricos, sob pena de condenar o ser 
humano ao desaparecimento. Percebeu-se que a capacidade de carga da Terra está próxima de níveis insustentáveis (Faria \& Carneiro, 2001).

Nas últimas décadas do século XX, concluiu-se, então, que o modelo de desenvolvimento tradicional como paradigma dominante estava gradativamente condenado. Com isso, surge a necessidade de sua substituição/renovação/inovação para outro patamar. Estava inaugurada, assim, a "era" denominada do "desenvolvimento sustentável" (Guimarães, 2001).

A partir desse novo paradigma conceitual de desenvolvimento da atividade turística, inicialmente voltada ao turismo de massa - o famoso binômio sol e praia -, encaminha-se para um novo tipo de valores e hábitos em que os indivíduos procuram melhoria de qualidade de vida, esta incluindo a procura de recursos naturais preservados, culturas diferenciadas, modos de vida peculiares, paisagens exuberantes etc., enfim, tudo que os faça esquecer, por alguns momentos, a racionalidade urbano-industrial das grandes metrópoles. Esse turismo alternativo é visto como o oposto do turismo convencional, prejudicial ao meio ambiente e, muitas vezes, ao modo de vida local, pois se caracteriza, justamente, pela tentativa de minimizar o impacto ambiental e sociocultural dos turistas em locais ainda pouco visitados (Waiberg, 2003).

Atualmente, existe uma variedade de tipos de turistas. ${ }^{4} \mathrm{Um}$ dos tipos que mais desperta a atenção, em termos de ser potencializador na busca de um desenvolvimento turístico sustentável, pelo forte apelo ecológico nas suas demandas, é como o descrito por Krippendorf (2001), ou seja, aquele que busca estabelecer contato maior com a população autóctone, procurando utilizar-se de uma infraestrutura não convencional, acomodando-se às mesmas condições e aos mesmos meios de vida (transporte, alimentação etc.) da população local. Esses turistas são considerados os mais desejáveis em áreas de preservação ambiental, principalmente naquelas cujas comunidades não conseguem ou não podem hospedar um turista que busca essencialmente conforto e mordomias. Ao mesmo tempo, são importantes para a conservação dos recursos naturais, por serem em menor número. Em geral, esses tipos de turista têm escolaridade superior e, teoricamente, visão mais realista sobre a problemática ambiental. Possivelmente, esse seria um demandante mais próximo do ideal, para áreas cuja capacidade de carga pode tornar-se uma problemática e/ou onde a comunidade local pretende controlar a dimensão de sua oferta turística.

Assim se pode afirmar que a:

4. Para a caracterização dos tipos de turistas, ver Krippendorf (2001).
[...] crise do modelo de turismo convencional e a crescente preocupação das populações dos países desenvolvidos e dos grandes centros urbanos pela melhoria de sua qualidade de vida permitiram uma mudança na demanda turística, que se enquadra numa grande transformação social, que assume como traços distintivos o resgate do individual e autêntico sobre o material e a padronização.... incluindo a volta à natureza nessa busca de autenticidade (Dias, 2003: 17).

Nessa perspectiva, o turismo ecológico aparece como alternativa de reprodução econômica para habitantes da zona rural, especialmente os pequenos agricultores familiares dos países subdesenvolvidos que, nos últimos anos, têm sofrido mais de perto as dificuldades econômicas impostas pelos ditames do modelo econômico do liberalismo de mercado.

Segundo Rocha e Brandenburg (2003), a trajetória da modernização na agricultura teve como conseqüência um dos mais graves desajustes sociais já vistos na história da humanidade. A modernidade causou no setor agrícola ambigüidades antagônicas, principalmente em países periféricos, como o Brasil, pois, ao mesmo tempo em que proporcionou melhores condições tecnológicas para produção e um conseqüente aumento de produtividade, fez com que ocorresse um processo de exclusão humana avassalador, o êxodo rural. Diante disso, o que se observa nos espaços rurais é que apenas os velhos e os jovens ficaram, os primeiros por não terem mais perspectivas, e os segundos por ainda não terem encontrado condições de se transferirem para as cidades.

Assim, para os pequenos agricultores familiares, torna-se imprescindível a criação de estratégias que compatibilizem, simultaneamente, a viabilidade econômica e a eqüidade social, com a autonomia política e a prudência ecológica, vistas como um único projeto de desenvolvimento rural sustentável. É válido lembrar também que, apesar dos diversos contratempos econômicos enfrentados pelo agricultor familiar nos últimos anos, é da excepcional capacidade de adaptação que vem sua habilidade de resistir ao "jogo" dialético do sistema hegemônico capitalista (Rocha \& Brandenburg, 2003).

Nesse contexto, o turismo não convencional - rural, ecológico, de aventura etc. - torna-se uma alternativa não definitiva, ou uma panacéia que resolverá todos os problemas dos agricultores familiares, mas torna-se especialmente importante, pois alia essa nova demanda turística da sociedade urbana com a necessidade de reprodução econômica dos pequenos agricultores familiares. Contudo, para que essa alternativa se concretize, há fortes limitantes que deverão ser considerados. É sob esta perspectiva que, no próximo tópico, se analisa o projeto da Fundação O Boticário em Guaraqueçaba. 


\section{O projeto Geração de Renda da Fundação 0 Boticário}

A Fundação O Boticário de Preservação da Natureza estabeleceu-se no município de Guaraqueçaba - PR, na comunidade do Morato, em 1993, fundando a Reserva Particular do Patrimônio Nacional - RPPN, denominada "Reserva Natural Morato", a qual abrange hoje 2.340 ha (Rocha, 2004). Nesse projeto, a Fundação O Boticário teve o apoio financeiro da ONG norte-americana The Nature Conservancy $-\mathrm{TNC}^{5}$. Nos seus projetos, esta ONG norte-americana pretende incentivar a preservação de parte da Mata Atlântica, considerada pela UNESCO como uma das mais importantes reservas da Biosfera e uma das mais ameaçadas.

No Morato, é destaque natural uma importante e bela cachoeira de 130 metros de altura e uma enorme figueira com raiz em forma de arco que atravessa o riacho Engenho. Esses dois locais, pela beleza, são alguns dos pontos turísticos mais visitados do município de Guaraqueçaba.

Antes da RPPN Salto Morato, implantada pela Fundação O Boticário de Proteção da Natureza, a área era ocupada por duas grandes fazendas de búfalos: a Fazenda Figueira e a Fazenda Salto do Morato e, por isso mesmo, no fim da década de 1990, encontrava-se com significativo estado de degradação ambiental, especialmente nas áreas mais baixas, nas quais eram utilizadas para pastagens e manejo dos animais. Segundo informações obtidas com os técnicos da Fundação O Boticário de Proteção à Natureza, antes de sua atuação na região, havia também cortes indiscriminados de espécies nativas, especialmente o palmito juçara, mesmo após ter sido implantada a APA de Guaraqueçaba em 1985 (Tommasino, 2002).

A intenção inicial da Instituição era investir, nos primeiros três anos de implantação da reserva, 600 mil dólares na montagem de infra-estrutura e na compra de equipamentos que possibilitassem o trabalho de pesquisadores, além de infra-estrutura necessária para motivar a demanda turística (Rocha, 2004).

Há que salientar que a implantação dessa reserva no município de Guaraqueçaba foi caracterizada, na época, pela polêmica da "americanização" dos recursos naturais da região. Segundo notícias da imprensa do Estado, a vinda de quinze técnicos da TNC para Guaraqueçaba, entre os anos de 1992 e 1993, gerou o temor e a polêmica, até certo ponto exagerada, de que o município seria vendido pelo valor de 90 milhões de dólares. Essa polêmica foi considerada por muitos infundada. Segundo um dos diretores da TNC, é apenas um boato popular, sem fundamento prático (Rocha, 2004).

5. Essa ONG americana é a principal parceira financeira da Fundação O Boticário de Preservação da Natureza.
Inicialmente, a Fundação O Boticário tinha como exclusiva preocupação a manutenção e a recuperação dos recursos naturais da Reserva Natural Morato. Eram preocupações de cunho preservacionista e de pesquisas. Não havia projetos para atuar com a comunidade local. Contudo, logo nos primeiros meses de sua atuação na região, seus técnicos se viram diante de uma questão pouco discutida quando da implantação da reserva: os problemas socioeconômicos que a comunidade local passou a ter, em função das restrições aos recursos naturais que agora estavam no interior da Reserva do Morato.

O conflito entre os guardas da reserva e os agricultores/coletores teve vários episódios, quase todos em função da coleta do palmito. Mesmo com as repressões à sua prática, o estoque dessa espécie no interior da reserva tornou-se raro, como relata o gerente da reserva: "Ainda temos palmito, mas está longe e de difícil acesso. Tem alguns aqui perto onde nós podemos cuidar. Os de longe nem 'eles' (referindo-se aos coletores clandestinos) conseguem chegar" (Rocha, 2004).

Mesmo que os técnicos da Fundação O Boticário aleguem que a comunidade do Morato estivesse passando por dificuldades socioeconômicas antes da instalação da reserva, não se pode negar que a moratória implantada pela política preservacionista dessa Fundação aos recursos florestais antes utilizados pela comunidade fez com que as condições de sobrevivência socioeconômicas desses agricultores se tornassem ainda mais difíceis. Como nos relata um antigo morador do Morato: "Antes era difícil, mas nós tinha a mata, se caçava, se pescava, se tinha uma rocinha [...] depois ficou meio difícil [...] depois eles chegaram (referindo-se à Fundação O Boticário) nós ficamos sem uma alternativa [...] é difícil ninguém quer mais ter roça" (Rocha, 2004).

Nota-se, em outras declarações obtidas nas entrevistas, segundo Rocha (2004), que a implantação da APA de Guaraqueçaba, em 1985, pouco inibia a atuação dos coletores de palmito na região. Essa inibição só foi concretizada após a instalação da RPPN Salto Morato em 1993. De outra forma, a fiscalização sobre os recursos naturais do Morato, antes pouco realizada pelos órgãos ambientais governamentais, foi delegada, intencionalmente ou não, aos técnicos e guardas da Fundação O Boticário de Proteção à Natureza (Rocha, 2004).

Assim, a situação econômica da comunidade local se agravou após as restrições aos recursos florestais localizados no interior da reserva Morato. Ou seja, a legislação em si não causava tantos transtornos para os habitantes da comunidade quanto a "privatização" da gestão dos recursos naturais da "agora” RPPN instalada lá.

Também está evidente, inicialmente, que não era intenção da Fundação O Boticário desenvolver projetos sociais em Guaraqueçaba. Foram as circunstâncias que a levaram a isso. A questão social foi um problema que surgiu logo nos primeiros meses de sua atuação, e a solução passou a ser a promoção de incentivos a práticas 
que utilizassem, o menos possível, os recursos naturais da região. Dessa forma, a demanda turística surgiu como fonte de renda para os moradores locais. A solução proposta para os problemas econômicos dos agricultores do Morato foi, portanto, uma estratégia "não agrícola": o artesanato impulsionado pelo turismo.

\section{O turismo na comunidade do Morato}

Foi para atender a uma demanda que influenciava diretamente a preservação dos recursos naturais que se pretendia preservar, no caso a área destinada à Reserva Salto do Morato, que a Fundação O Boticário começou a atuar no apoio a projetos de geração de renda para a comunidade local (Rocha, 2004).

Seguindo a concepção pregada nos organismos internacionais, como FAO, ONU, Banco Mundial e BID, e que também muitas ONGs seguem, é a pobreza que gera, e é simultaneamente resultado da deteriorização ambiental. Por essa lógica, são os pobres, e não os ricos, que determinam o uso exaustivo dos recursos naturais que estão à sua volta. Os problemas sociais devem ser resolvidos, não por questões humanitárias ou filantrópicas, mas para que sejam preservados os recursos ambientais. Alguns denominam esse tipo de sustentabilidade de sustentabilidade ponte (Tommasino 2003). Essa teoria pressupõe que os mais pobres utilizam de forma inapropriada os recursos naturais (Diegues, 2000).

O projeto de apoio às atividades artesanais da comunidade local, em função do comércio com os turistas que visitariam a Reserva do Salto do Morato, a partir de meados de 1997, contou com o apoio da Fundação Interamericana - organização independente do governo americano, criada em 1969, como alternativa experimental aos programas de ajuda externa dos Estados Unidos para a América Latina e o Caribe. A Fundação Interamericana pretendia promover estratégias de desenvolvimento que possibilitassem a melhoria da qualidade de vida das populações mais pobres do continente.

Com esse intuito é que a Fundação Interamericana criou um fundo para apoio a projetos denominados de ecodesenvolvimento. No Brasil, esse fundo de recursos seria gerenciado pela Fundação O Boticário objetivando apoiar projetos que:

- visem à diminuição da pressão sobre os recursos naturais e fomentem atividades que garantam a proteção dos ambientes onde serão desenvolvidos;

- aliem esforços ambientais e sociais que gerem alternativas sustentáveis de renda e, principalmente, que sirvam de modelo para outras iniciativas;

- fortaleçam valores que levem à prosperidade e à qualidade de vida, pela educação e mobilização, pelo cuidado com a natureza e investimento social (Fundação O Boticário, 2003 - www.fundacaooboticario.org.br).
O projeto desenvolvido em Guaraqueçaba foi denominado Programa de Geração de Renda para a Comunidade do Morato. A expectativa era proporcionar aos moradores da localidade formas alternativas de sustentabilidade econômica, visando especialmente à diminuição da coleta de palmito na região. Em outras palavras, procuravam-se fórmulas para evitar a utilização dos recursos florestais da região, especialmente aqueles localizados agora no interior da "Reserva da Fundação O Boticário" (Rocha, 2004).

Inicialmente, a Fundação O Boticário financiou um curso de artesanato destinado aos moradores do Morato que estivessem dispostos a se integrar no projeto de redirecionamento da atividade produtiva na região: da agricultura para o turismo, supondo que esse seria mais sustentável que o primeiro. O curso visava a capacitá-los a confeccionarem cestas que tinham como matéria-prima o jungo, o tabuão, abundantes na região, além de corda ${ }^{6}$ e arame, adquiridos fora da região, por intermédio da Fundação O Boticário.

A familiaridade dos moradores com o artesanato, pois já confeccionavam artefatos rústicos para uso doméstico, possibilitou o sucesso do curso proposto pela Fundação O Boticário. Assim, a grande maioria das 35 famílias do Morato, em poucos meses, já estava apta a confeccionar cestinhas (Rocha, 2004).

A produção mensal, no início do projeto, girava em torno de 500 cestas por mês, sendo que $80 \%$ da produção era destinada às lojas de O Boticário, ${ }^{7}$ e, segundo informações, não as comercializavam, mas as utilizavam como utensílio interno das lojas para facilitar as compras de seus produtos. Os 20\% restantes da produção eram comercializados diretamente com os turistas que visitavam a reserva.

Segundo declarações dos moradores da região, no início do projeto a própria administração da reserva Salto Morato incentivava os turistas a adquirirem as cestas, o que incentivava que a comercialização tivesse uma demanda significativa. Isso permitiu que a produção de cestas, no seu pico mais alto, entre 1997 e 1999, proporcionasse em média uma receita familiar em torno de 400 reais para cada uma das famílias associadas à Associação de Artesãos do Morato - AAM. Tal valor permitiu que, durante os três primeiros anos do projeto, a comunidade passasse por "uma época boa", como destacou o presidente da AAM em janeiro de 2003:

6. Há comentários entre os moradores do Morato que, em vez de cordas se usava, às vezes, o cipó, recurso florestal abundante na região, mas que, pela legislação ambiental, tem sua utilização proibida. Isso também contribuiu para inviabilizar a continuação do projeto, pois o Ibama começou a fiscalizar e a cobrar da Fundação O Boticário uma outra alternativa. Essa informação foi veementemente contestada pelo gerente da Reserva do Morato (Rocha, 2004).

7. Nas entrevistas concedidas pelo gerente da Reserva Salto do Morato, ele fez questão de ressaltar a independência entre as lojas do $\mathrm{O}$ Boticário e a Fundação O Boticário de Preservação à Natureza. 
Foi uma época boa, a gente fazia as cestas, eles levavam e logo já pagavam. Parecia que aquilo ia continuar pra sempre. Numa reunião o [...] disse pra nós: "O negócio de vocês só vai acabar se vocês quiserem, enquanto eu tiver aqui vou fazer de tudo pra que continue. Vocês agora são artesãos e isso é que vai dá futuro aqui pro Morato" (Rocha, 2004).

Essa receita, aliada às dificuldades encontradas no plantio por causa das restrições ambientais e a penosidade das atividades agrícolas, fizeram com que a maioria dos moradores do Morato abandonasse as lavouras, especialmente aquelas destinadas à comercialização, e passassem a se dedicar quase que exclusivamente ao comércio das cestas com os turistas que visitavam a Reserva Salto do Morato. Consta que somente um agricultor, um dos mais antigos moradores do local, continuou com atividades agrícolas com fins comerciais, como a criação de gado e o cultivo da banana, mas ele, por problemas de saúde, em fevereiro de 2003, também havia diminuído suas criações e plantações e vendido parte de suas terras para um empresário de Curitiba (Rocha, 2004).

A partir da metade do ano de 2001 diminuiu a demanda que O Boticário tinha pelas "cestinhas da Associação do Morato". Foi uma diminuição drástica. Em entrevistas realizadas na comunidade, no mês de janeiro de 2002, percebiam-se os sinais dessa diminuição. Como declarou o presidente da Associação de Moradores do Morato:

Estamos a quatro meses sem receber, estão nos devendo até uma encomenda que levaram em setembro [...] não fazem mais encomenda. [...] Nem o material para fazer mais cestas eles estão mandando [...] nós só ficamos na dependência dos turistas [...] tá dando muito pouco (Rocha, 2004: 176).

A constatação que se faz, pela análise das entrevistas realizadas (Rocha, 2004) entre os moradores do Morato, é que, para o êxito da comercialização das cestas da comunidade, novos mercados consumidores terão de ser buscados, além de turistas para visitar o Salto, considerando-se que esses são em número muito

8. Existem duas associações na comunidade do Morato: uma de artesãos, ligada inicialmente ao projeto da Fundação O Boticário e outra de moradores, esta mais crítica à atuação da Fundação O Boticário (Rocha, 2004). pequeno. ${ }^{9}$ Além disso, por não haver um ponto comercial definido, as vendas para os visitantes são poucas. ${ }^{10}$

Outro grande problema para a comercialização das cestinhas fabricadas pela Associação de Artesãos do Morato é a estrada que dá acesso à reserva. A situação precária da estrada limita o acesso de turistas para a visitação do Salto, além de não permitir a viabilidade econômica de comercialização em centros maiores, em virtude do alto custo do transporte. Como conseqüência, há um comércio cada vez mais fraco das cestas. Contudo, a solução para o problema parece que está ainda longe de acontecer, pois não há previsão, a curto prazo, de que ocorram projetos concretos para a melhoria da estrada que dá acesso ao Morato.

Segundo informações do Gerente da Reserva do Morato, das 500 cestas produzidas no início do projeto, em 2003 eram produzidas em torno de 150. E essa parece ainda ser uma estimativa bastante otimista, pois esse número não foi confirmado nas entrevistas com os moradores: "[...] agora ninguém tá produzindo nada, já faz uns três meses que parou tudo [...] estamos esperando [...] a gente não sabe o que vai dar, se ainda vão comprar, se não vão [...] (Rocha, 2004: 182).

Ainda que a Associação de Artesãos do Morato não possua o controle efetivo da comercialização, verificou-se que o número de cestas produzidas e comercializadas com os turistas que visitavam o local, a única demanda efetiva em fevereiro de 2003, era muito pequeno.

Mesmo que, pelas informações do gerente da reserva do Morato, a Fundação O Boticário já tivesse investido, de 1997 a 2003, em torno de 100 mil reais só em projetos de geração de renda para a comunidade do Morato, esses projetos não renderam os resultados teoricamente esperados.

Há um claro desfoque entre os objetivos da Fundação O Boticário de Preservação à Natureza e as necessidades autênticas dos moradores do Morato. O fato é que, mesmo com a boa vontade dos agentes executores desse projeto e os investimentos já feitos, essas ações foram insuficientes para proporcionar garantia de qualidade de vida, como consta nos ideais propostos inicialmente.

$\mathrm{O}$ último dos projetos de geração de renda para a comunidade do Morato, desenvolvido pela Fundação O Boticário (em andamento em fevereiro de 2003) é a

9. A Reserva Salto do Morato recebe em média 7.500 turistas/ano (informação obtida com o gerente da Reserva Salto do Morato, em 20 de fevereiro de 2003, por e-mail) (Rocha, 2004).

10. Ao contrário da informação prestada pelo gerente da reserva, que afirmou que as cestas que os moradores colocam "na frente de suas casas" acabam sendo vendidas, as informações que se têm é de que existia em fevereiro de 2003 um estoque relativamente grande de cestas que não conseguiam ser vendidas. Num dos pontos-de-venda principais da localidade, na entrada do Morato (O Bar do seu Sílvio), existia um bom estoque de cestas, e algumas estavam ali há mais de um ano. Entrevista de 28/01/2003 (Rocha, 2004). 
construção de um barracão comunitário, que terá parte financiada pela Fundação Interamericana. Num orçamento estimado em R \$ 115.000,00, ${ }^{11}$ o barracão servirá como local de confecção e de comercialização das cestas, além de oferecer um escritório para administração da associação dos artesãos, uma sala onde poderão ser ministrados cursos e aulas e um salão de festas que ficará à disposição da comunidade. O prédio, em fevereiro de 2003, estava ainda em fase de implantação, pois, segundo informações, é uma obra pré-moldada construída em Curitiba e que virá para Guaraqueçaba com um caminhão guincho, empreendimento que, pelas entrevistas, se tornava impossível com o estado da rodovia na época (rodovia que liga a comunidade do Morato à estrada principal de acesso ao município) (Rocha, 2004).

O aspecto significativo desse projeto é que a construção do barracão destinado à comunidade local foi realizada longe dela, sem o uso da mão-de-obra local. E, entre os moradores locais, poucos sabiam exatamente como iria funcionar tal projeto. Alguns se mostraram desconfiados de suas verdadeiras intenções.

Além disso, entre os moradores do Morato, há muitas controvérsias sobre a viabilidade desse barracão. Segundo o presidente da Associação de Moradores, é “ainda duvidoso" que, com a construção do barracão, aumente o volume de cestas vendidas, já que o número de turistas não consegue absorver nem $50 \%$ da produção.

Conforme declarou outro entrevistado, alguns moradores prefeririam que, em vez da construção de um local para venda de cestas, se investisse a verba, ou parte dela, em outro empreendimento, como na compra de um veículo que possibilitasse levar as cestas para centros maiores, como Curitiba e Paranaguá, ou na compra ou locação de um ponto comercial, também num grande centro urbano. A estratégia, nesse caso, seria encontrar mecanismos que pudessem favorecer a comercialização das cestas, já que o mercado para os turistas que visitam a região está cada vez menor. Tais possibilidades, contudo, nem foram levantadas pelo gerente da Reserva Salto do Morato nas suas entrevistas (Rocha, 2004).

Enfim, a estratégia para geração de renda na comunidade do Morato, apesar das intenções iniciais da Fundação O Boticário de Preservação à Natureza de proporcionar aumento de renda para seus moradores, pelo incentivo à comercialização do artesanato com os turistas que visitam o local, não passou de solução paliativa e pontual, pois não conseguiu reverter o quadro precário em que se encontra a maioria das famílias do local, além de não ter durado muitos anos. Esse "desfoque" das demandas sociais do local talvez seja o reflexo da concepção que se tem de que a agricultura em Guaraqueçaba causa sérios desgastes ambientais, e de que as soluções

11. Destes $\mathrm{R} \$ 115.000, \mathrm{R} \$ 48.000,00$ foram a contrapartida da Fundação o Boticário de Preservação da Natureza. (Informação prestada pelo gerente da Reserva Salto Morato via e-mail em 20/02/2003) (Rocha, 2004). "não agrícolas" seriam mais viáveis na tentativa de manutenção desses recursos. Também deve-se perceber que a "[...] busca da sustentabilidade fundamenta-se, [...] (na maioria dos casos), em argumentos cujo universo de referência situa-se muito além do contexto local" (Raynaut, 2002: 247) (Acréscimos J.M.R.). Nesse caso, duas organizações norte-americanas, a TNC e a Fundação Interamericana.

\section{Considerações finais}

A partir dos anos de 1990, a busca do turismo tradicional, baseado em sol e praia, começa a mudar. O crescimento do movimento ambientalista, aliado à neurose coletiva de beira de praia, fez com que um novo grupo de turistas, oriundos especialmente das classes sociais A e B e alguns denominados "mochileiros", passassem a buscar novas alternativas de lazer. Muito antes do relatório Brundtland de 1987, já em 1980, na Declaração sobre Turismo Mundial de Manila, essa nova tendência turística já era diagnosticada (Waiberg, 2003).

No início da década de 1980, havia forte tendência em se admitir que o desenvolvimento das atividades de férias e tempo livre e uma saudável gestão do meio ambiente seriam dois elementos essenciais e interdependentes de um rico processo de desenvolvimento sustentável. No ano de 1982, a OMT e o Pnuma divulgaram a Declaração sobre Turismo e Meio Ambiente, fazendo constar que a satisfação das exigências para o desenvolvimento do turismo não pode ser prejudicial aos interesses culturais, ambientais, sociais e econômicos das comunidades e, sobretudo, dos recursos naturais, atração fundamental desse novo tipo de turismo (Theobald, 2001).

Ao contrário das fórmulas de desenvolvimento do turismo tradicional que, muitas vezes, sacrifica o futuro dos recursos naturais locais por privilegiar ganhos econômicos e financeiros imediatos, como empreendimentos imobiliários em áreas verdes nobres que prejudicam, em um futuro muito próximo, não só o meio ambiente, mas a sociedade local, o turismo alternativo-ecológico prima pela aliança das demandas dos turistas com a possibilidade de se manter pouco alterada a rotina social e o meio ambiente da região. Contudo, não se deve perder de vista que, em muitos locais, ainda se faz necessário um planejamento mais efetivo para poder usufruir desse processo. Muitas vezes, estratégias bem-intencionadas não levam em conta a trajetória local, historicamente construída, pois não se dispõem a verificar se os mecanismos sociais e econômicos para potencializar os "ganhos com os turistas alternativos" estão de acordo com uma demanda endogenamente articulada pelas redes comunitárias de convivência e, principalmente, de reprodução econômica. Esse foi talvez o aspecto que comprometeu de forma definitiva o projeto de incentivo a um "turismo sustentável” na comunidade do Morato. 
A concepção do projeto da Fundação O Boticário para incrementar a renda da comunidade local baseou-se na perspectiva preservacionista. Nesta, a agricultura, mesmo aquela em pequena escala desenvolvida por agricultores familiares, é fonte de degradação ambiental. Havia clara intenção de motivar atividades turísticoartesanais para evitar que os moradores locais pressionassem os recursos naturais da região, considerados patrimônio natural da humanidade. Logo, a preocupação com a preservação ambiental norteou as ações que envolviam a problemática social, ou seja, em última análise, resolver o problema de manutenção econômica dos agricultores locais era uma condição para que se atingisse a preservação da natureza, este sim objetivo final, se não o único (Raynaut et al., 2003).

\section{Referências bibliográficas}

ACSELRAD, Henri. 2001. Políticas ambientais e construção democrática. In: VIANA, Gilney, SILVA, Marin \& DINIZ, Nilo. O desafio da sustentabilidade: um debate socioambiental no Brasil. São Paulo: Fundação Perseu Abramo. p. 75-96.

BARRETTO, M. 2004. Relações entre visitantes e visitados: um retrospecto dos estudos socio- antropológicos. Turismo em Análise. São Paulo: CRP/ECA/USP: Aleph, v. 15, n. 2, p. 133-149.

BRUNDTLAND, G. H. 1991. Nosso futuro comum. 2 ed. Rio de Janeiro: FGV.

CARSON, Rachel. 1962. The silent spring. Boston: Houghton Mifflin.

DIAS, Reinaldo. 2003. Turismo sustentável e meio ambiente. São Paulo: Atlas.

DIEGUES, A. C. 2000. Etnoconservação da natureza: enfoques alternativos. In: DIEGUES, A. C. (Org.) Etnoconservação novos rumos para a proteção da natureza nos trópicos. 2.ed. São Paulo: Nupaub/Hucitec.

FARIA, D. S. \& CARNEIRO, K. S. 2001. Sustentabilidade ecológica no turismo. Brasília: Ed. Universidade de Brasília.

FOLADORI, Guillermo. 1999. Los límites del desarrollo sustentable. Ediciones de la Banda Oriental, Revista Trabajo y Capital, Montevideo, Uruguay.

FUNDAÇÃO O BOTICÁRIO DE PRESERVAÇÃO DA NATUREZA. Disponível em: $<$ http://www.fundacaooboticario.org.br>. Acesso em: 23 jun. 2003.

GUIMARÃES, R. 2002. A ética da sustentabilidade e a formação de políticas de desenvolvimento. In: VIANA, G. \& SILVA, M. (Org.). O desafio da sustentabilidade: um debate socioambiental no Brasil. São Paulo: Fundação Perseu Abramo. p. 43-72.

KRIPPENDORF, Jost. 2001. Sociologia do turismo: para uma nova compreensão do lazer e das viagens. 2. ed. São Paulo: Aleph.

LE PRESTRE, Philippe. 2000. Ecopolitica internacional. São Paulo: SENAC-SP.

LEIS, Héctor. 1999. A modernidade insustentável. Petrópolis: Vozes; Florianópolis: UFSC.

MARZALL, K. 1999. Indicadores de sustentabilidade para agroecossistemas. Dissertação (Mestrado) - Programa de Pós-Graduação em Fitotecnia da UFRGS, Porto Alegre.

MEADOWS, D.G. et al. 1972. Limites do crescimento. São Paulo: Perspectiva.

MIDDLETON, Neil \& O'KEEFE, Phil. 2001. Redefining sustainable development. London: Sterling, VA: Pluto Press.

MORIN, Edgar. 1997. Por um pensamento ecologisado. In: CASTRO, E. \& PINTON, F. Faces do trópico úmido. Belém: UfPA/NAEA. p. 53-77.
NEDER, Ricardo Toledo. 2001. Para uma regulação pública ambiental pós-desenvolvimentista no Brasil. In: CAVALCANTI, Clóvis. Meio ambiente, desenvolvimento sustentável e políticas públicas. São Paulo: Cortez Recife: Fundação Joaquim Nabuco. p. 248-259.

RAYNAUT, Claude. 1994. O desenvolvimento e as lógicas de mudança: a necessidade de uma abordagem holistica. Cadernos de Desenvolvimento e Meio Ambiente. Curitiba: Ed. da UFPR/GRID, n 1.

RAYNAUT, Claude, ZANONI, Magda \& LANA, Paulo C. 2002. Desenvolvimento e meio ambiente: em busca da interdisciplinaridade. Pesquisas urbanas e rurais. Curitiba: Ed. da UPPR. p. 235-248.

ROCHA, J. M. 2004. A logica das políticas de desenvolvimento rural para áreas de proteção ambiental: a sustentabilidade desfocada. O caso de Guaraqueçaba - PR. Tese (Doutorado em Meio Ambiente e Desenvolvimento) - Universidade Federal do Paraná, Curitiba.

2000. A gestão dos recursos naturais: uma perspectiva de sustentabilidade baseada nas aspirações do "lugar". Estudo \& Debate. Lajeado: UNIVATES, ano 7, n. 1-2, p. 167-188.

2002a. A sustentabilidade ambiental e economia de livre mercado: a impossível conciliação. Estudo do CEPE - Centro de Estudos e Pesquisas Econômicas. Santa Cruz do Sul: EDUnISC, jan./dez., p. 127-144.

. 2002b. As limitações disciplinares diante da problemática ambiental: os novos pressupostos da ciência. REDES. Santa Cruz do Sul - RS: UNISC, v. 7, n. 1, p. 35-50, jan./abr.

ROCHA, J. M. \& BRANDERBUEG, A. 2003. Limites e desafios da agricultura familiar: a sustentabilidade em questão. REDES. Santa Cruz do Sul - RS: UNISC, v. 8, n. 2, p. 93-104, maio/ago.

SACHS, Ignacy. 1993. Estratégias de transição para o século XXI: desenvolvimento e meio ambiente. São Paulo: Studio Nobel: Fundação do Desenvolvimento Administrativo.

SESSA, Alberto. 1993. Turismo e politica de desenvolvimento. Porto Alegre: Uniontur.

THEOBALD, W. F. (Org.). 2001. Turismo global. São Paulo: SENAC-SP.

TOMMASINO, H. 2002. Sustentabilidad ou insustentabilidad puente? Análisis de la producción animal en el municipio (APA) de Guaraqueçaba, Paraná (BR). 229f. Tese (Doutorado em Meio Ambiente e Desenvolvimento) - MADE, Universidade Federal do Paraná, Curitiba.

TRIGO, Luiz G. G. 1996. Turismo e qualidade: tendências contemporâneas. Campinas, SP: Papirus.

URBAN, Tereza. 2001. Missão (quase) impossivel: aventuras e desventuras do movimento ambientalista no Brasil. São Paulo: Peirópolis.

WAINBERG, J. A. 2003. O movimento rurístico: olhadelas e suspiros em busca da singularidade alheia. In: GASTAL, S. \& CASTROGIOVANNI, A. C. (Orgs.). Turismo na pós-modernidade: (des)inquietaçōes. Porto Alegre: EDIPURS. p. 9-20.

Recebido em: 01/07/2005.

Aprovado em: 24/04/2006. 